\title{
The Effects of a Motivational Intervention on Improving the Writing Productivity of Students with Learning Disabilities
}

\author{
Matthias Grünke ${ }^{1}$ \\ ${ }^{1}$ Department of Special Education \& Rehabilitation, University of Cologne, Germany \\ Correspondence: Matthias Grünke, Department of Special Education \& Rehabilitation, University of Cologne, \\ Klosterstr. 79b, 50931 Cologne, Germany.
}

Received: October 16, 2018

Accepted: November 20, 2018

Online Published: February 26, 2019

doi:10.5539/ies.v12n3p36

URL: https://doi.org/10.5539/ies.v12n3p36

\begin{abstract}
The purpose of this study was to implement and evaluate a motivational intervention that consisted of explicit timing, immediate feedback through self-scoring, and display of high scores with the goal of encouraging four students with learning disabilities to write longer stories. All participants were initially very unwilling to engage in text production. An ABA reversal design was used to assess the effectiveness of the approach. Immediately after the treatment, the subjects started to write more extensive stories. However, this effect ended abruptly once the intervention was terminated. The study's results show that, even for very reluctant students with learning disabilities, writing motivation can be significantly enhanced with relatively little effort. All the participants reported enjoying the treatment. The paper ends with a discussion of the experiment's limitations and the practical implications of the findings.
\end{abstract}

Keywords: writing performance, learning disabilities, motivational system, single-case reversal design

\section{Introduction}

Many students, especially those with learning disabilities, resent writing (Troia, Shankland, \& Wolbers, 2012). The activity of putting thoughts on paper or a computer screen is very complex. A lot of children shun such tasks because the cognitive processes involved in text composition are extraordinarily arduous. Writers need to (among many other tasks) demonstrate automaticity with prerequisite skills (handwriting, spelling, grammar rules, etc.), activate their knowledge about relevant topics and genre conventions, be aware of their prospective audience, consider the purpose of their efforts, organize their ideas, and monitor their endeavors (Santangelo, 2014). In fact, text production is often viewed as the most demanding school-related language activity (Fayol, Alamargot, \& Berninger, 2012). Students with learning disabilities are especially at risk for developing severe writing difficulties. These young people "fail to develop the knowledge, skill, will, and self-regulation necessary to succeed in key subject areas" (Grünke \& Morrison Cavendish, 2016, p. 1), thus making text composition often seem too demanding.

Given the importance of written communication, language-arts teachers need to equip their students with the skills necessary to translate ideas into written form. According to the National Commission on Writing for America's Families, Schools, and Colleges (2004), writing is so important that "individual opportunity in the United States depends critically on the ability to present one's thoughts coherently, cogently, and persuasively on paper" (p. 5). This applies not just to the United States but to all literate societies. Fortunately, the research base regarding effective writing instruction has advanced a great deal over the last two decades, especially concerning interventions for children and adolescents with learning disabilities (Gillespie \& Graham, 2014; Graham, MacArthur, \& Fitzgerald, 2013; Kaldenberg, Ganzeveld, Hosp, \& Rodgers, 2016; Troia, 2010).

The majority of studies that researchers have included in literature reviews and meta-analyses of writing interventions for special needs students (see, e.g., Cook \& Bennett, 2014; Datchuk \& Kubina, 2013; Gillespie \& Graham, 2014; Rogers \& Graham, 2008) are focused on the self-regulated strategy development (SRSD) approach (Graham \& Harris, 1996). SRSD is a six-step instructional model that provides a framework for teaching every key activity in the writing process, as determined according to the most influential theories of text production (see, e.g., Bereiter \& Scardamalia, 1987; Hayes \& Flower, 1980; Zimmerman \& Risemberg, 1997). There are three such activities: planning, translating, and revising. Many strategies can be used to deliver the skills for successful writing on the basis of SRSD, including FIX (Sherman \& De La Paz, 2015), POW \& WWW (Mason, Harris, \& 
Graham, 2004), and STOP \& DARE (De La Paz, 2001).

However, even the most effective approach will not yield the intended results, if students refuse to write because they deem it to be too laborious and wearisome. In a widely cited article on the quality indicators for effective text-production training entitled "What is missing from current writing intervention programs?", De Caso and García (2006) suggested a solution: writing motivation programs. Helpfully, many time-tested educational arrangements focus on influencing the processes that initiate, guide, and maintain students' goal-oriented behaviors.

In several studies, researchers have successfully implemented the strategies of explicit timing, providing immediate feedback through self-scoring, and displaying high scores to increase the motivation to produce texts among children with learning disabilities (Van Houten, Hill, \& Parsons, 1976; Van Houten \& McKillop, 1977; Van Houten, Morrison, Jarvis, \& McDonald, 1974). When applying explicit timing, the teacher gives the students a certain task, informs them of the time interval to complete it, and observes them as they try to be as effective as possible within the given time frame (Van Houten \& Thompson, 1976). When immediate feedback is provided through self-scoring, learners monitor their own performance by assessing the relevant target variable at the end of an assignment (Light, McKeachie, \& Lin, 1988). Prominently displaying students' high scores (e.g., on a poster hung on the classroom wall) is an effective positive reinforcement technique that has often been used in school settings (Archer \& Hughes, 2011; Prater, 2018).

There are several fairly recent studies on the effectiveness of the aforementioned motivational methods. For example, Duhon, House, Hastings, Poncy, and Solomon (2015), Grays, Rhymer, and Swartzmiller (2017) as well as Wells, Sheehey, and Sheehey (2017) used these techniques to improve mathematics fluency in elementary and middle school students. McDaniel, Jolivette, and Ennis (2013) demonstrated their positive impact the on the oral reading ability of a third grader with emotional and behavioral problems. But even though research interest in motivational systems to increase academic productivity is still alive in the scientific community, there are only two published papers on the aforementioned methods for improving writing performance in students with learning disabilities: Grünke, Sperling, and Burke (2017) and Grünke, Knaak, and Hisgen (2018). In both studies, explicit timing, immediate feedback through self-scoring, and displayed high scores were extremely effective; the children (who were 10 or 11 years old) were initially very unmotivated but went on to produce comparatively long texts. The purpose of this case report was to add to the limited existing findings on the benefits of these motivational writing-productivity techniques by considering a sample of four students with learning disabilities who were slightly older than those in the two prior experiments.

\section{Method}

\subsection{Setting and Participants}

The four participants are labeled here as Adrian, Bella, Christin, and Dominik (names changed for anonymity). Bella and Christin (both female) were 14 years old, and Adrian and Dominik (both male) were 12 years old. All four attended the same special school for students with moderate general-learning disabilities. It is located in a rural area outside of a major city in North Rhine-Westphalia (Germany). None of the students came from an immigrant background. All had been diagnosed with a learning disability by a multi-professional team and demonstrated a distinctive discrepancy between expected and actual achievement in reading and arithmetic. According to their teacher, their spelling skills were acceptable, but they were not able to compose text well. Whenever required to write something, they usually produced only one or two short sentences.

\subsection{Dependent Variable and Experimental Design}

Writing performance was assessed using a general-outcome measure of overall writing ability (McMaster \& Espin, 2007) consisting of counting the number of total words written (TWW), disregarding spelling errors (Furey, Marcotte, Hintze, \& Shackett, 2016). This measurement's reliability was determined by having two observers independently review the texts: an interventionist (see below) and a student assistant. The interrater agreement was $100 \%$.

An ABA reversal plan (Ledford \& Gast, 2018) was employed to analyze the motivational system's effects. This design consisted of a baseline condition (A1), followed by a treatment phase (B) and then a return to the baseline condition (A2). Each of the three phases was composed of five daily probes. Adrian was ill on the first day of the study; apart from that, all four students were present during the whole experiment. The ABA design was appropriate because we expected that TWW would change depending on whether the motivational system was in place. The performance was not anticipated to remain at a high level after the treatment was withdrawn. According to Tawney and Gast (1984), the ABA plan is the simplest single-case design that can identify functional 
relationships.

\subsection{Procedures}

During the study, the four participants met with a 25 -year-old female special-education graduate college student (who had previously worked as a teacher's aid and had ample experience in instructing children) in a resource room of the school for 15 to 30 minutes during the third period each day (9:50 to 10:35 A.M.). In the first baseline phase (A1), the participants randomly selected two writing prompts (see Marks, 2012) from a box and then produced a story about one of them. All the chosen prompts were thrown away after the students had reviewed them. The students then composed their texts on 8.27 - by 11.69-inch notebook paper. They were not explicitly motivated or instructed in any way, and they had no time limits. However, the participants all finished the narratives in less than 5 minutes. After completing their texts, the students filed them in a plastic folder.

At the beginning of the B phase, the graduate student presented Adrian, Bella, Christin, and Dominik with a chart that depicted their progress up to that point. She highlighted that they had done well so far but noted that there was still room for improvement. The college student also praised the subjects for their accomplishments and inserted index cards with their previous TWW high scores into cellophane windows on the outside of the folders (see Figure 1).

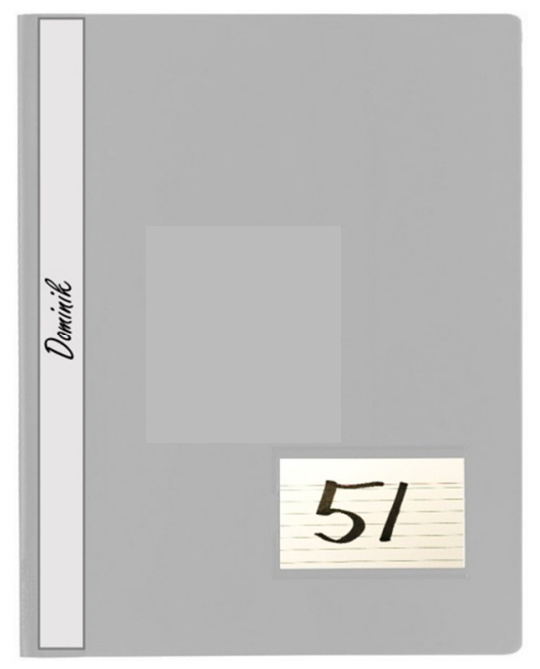

Figure 1. Example of a plastic folder with a high score on the exterior

In the B phrase, as in the first A phase, Adrian, Bella, Christin, and Dominik each selected two writing prompts from the box and produced a story. This time, however, the college student explained to them that they were granted exactly ten minutes to finish the task. A large timer on the teacher's desk allowed everyone to see the remaining time, and it emitted an acoustic signal after 10 minutes. Upon finishing the assignment, the participants counted their TWW and recorded that value at the bottom of their texts. The self-scoring took 5 to 10 minutes. Even though it was rather tedious to count every single word, Adrian, Bella, Christin, and Dominik enjoyed this procedure and were proud of their achievements. The final TWW high scores used in the charts were not based on the participants' counts, but on the totals that the college student and the assistant agreed upon (see above). However, the range of these deviations was only one to five words.

The second A phase resembled the first one. The participants again produced a story based on one of two selected prompts. Even though the students wanted to continue the self-scoring procedure (i.e., to have access to their charts and to use the timer), they were required to finish their assignment without this procedure.

\subsection{Treatment Fidelity and Social Validity}

Prior to the study, the author prepared the college student for the assignment across three 45 -minute meetings that focused on how to execute the performance tests and deliver instructions during the B phase. They stayed in close contact (talking at least every other day) to make sure that the experiment went according to plan. To capture the participants' impressions of the study's motivational tools, the graduate student conducted informal individual interviews with them at the end of the second A phase and recorded their responses. 


\section{Results}

The motivational program's effects on the students' writing productivity are shown in Figure 1. The calculations and figures were generated using the scan package for R by Wilbert (2018).

$\mathrm{A} 1$

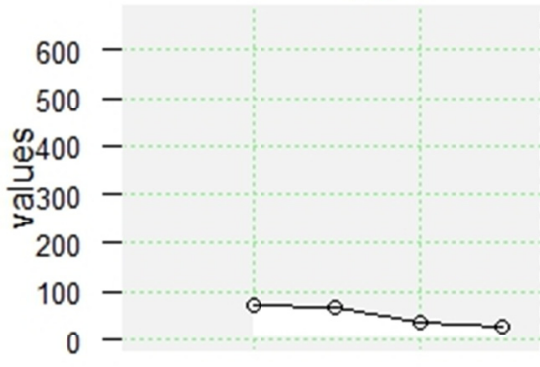

$\mathrm{A} 1$

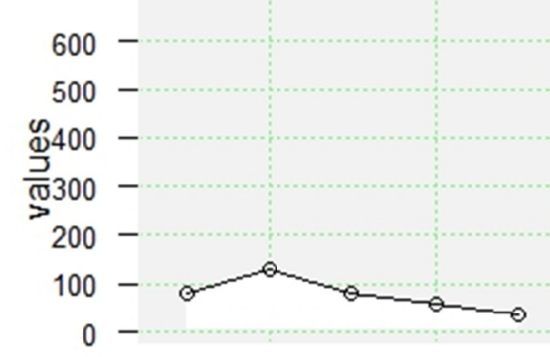

B

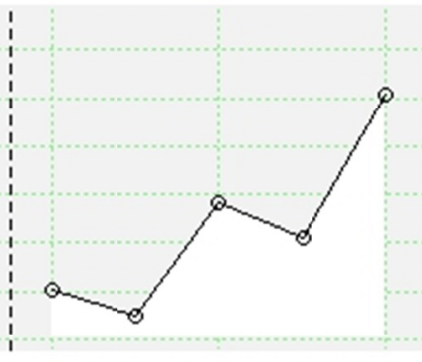

B

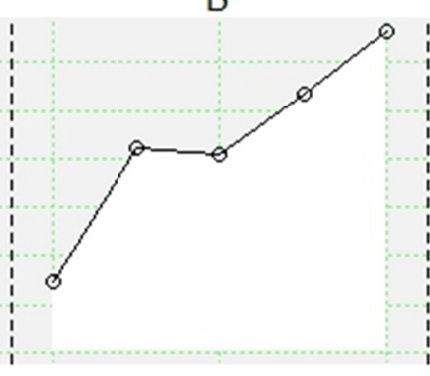

A2

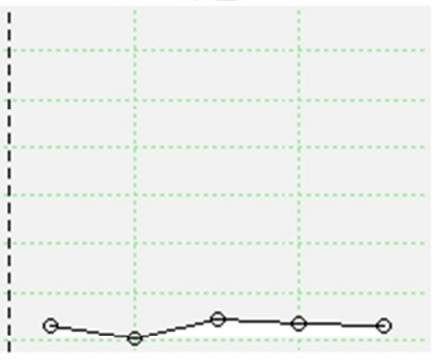

A2

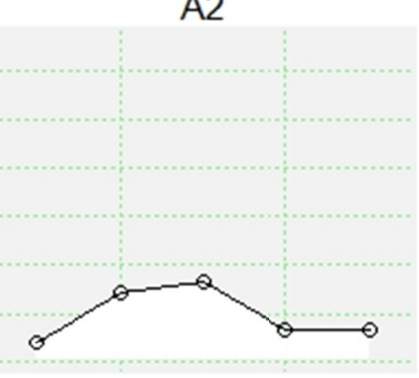

A1

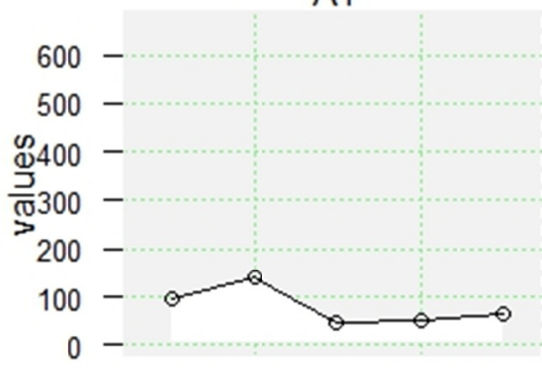

A1

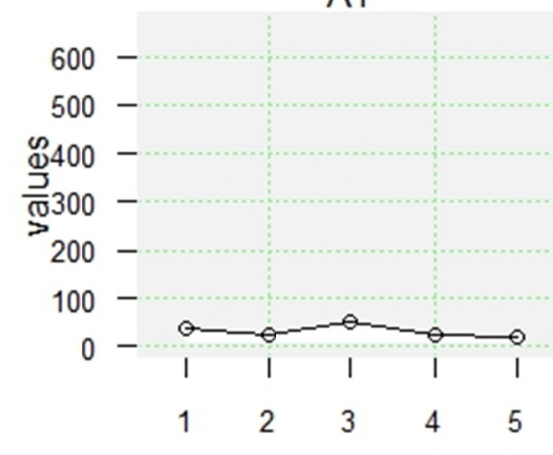

B

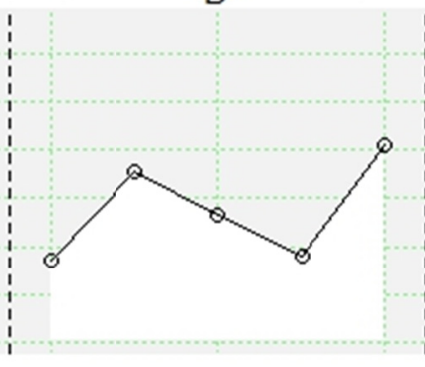

B

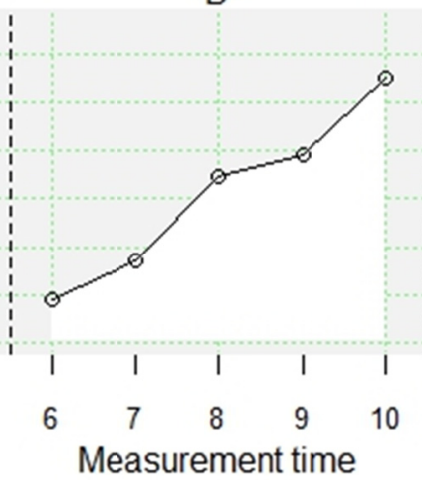

A2

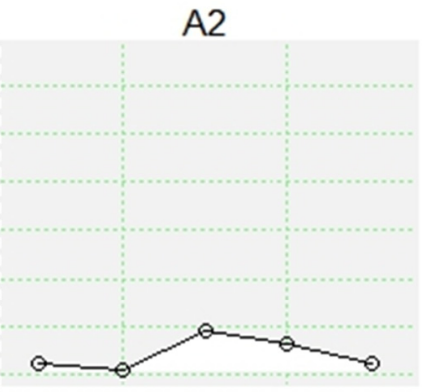

A2

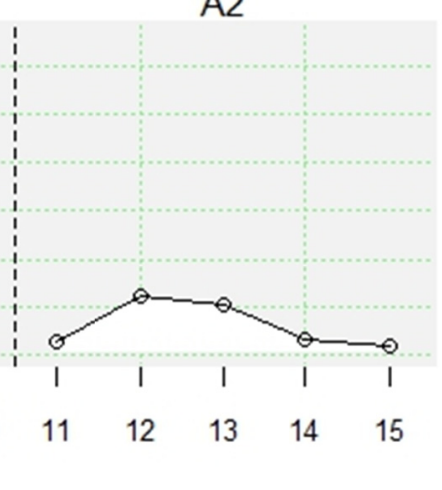

Figure 2. Number of TWW for Adrian, Bella, Christin, and Dominik in the three phases 
The participants had rather stable baselines, followed by improved performance during the $\mathrm{B}$ phase and a return to low scores in the A2 phase. The scores for the A1 and A2 phases, as compared to those in the B phase, showed $80 \%$ nonoverlapping data (PND, Scruggs \& Mastropieri, 1998) for Adrian and Bella, and 100\% nonoverlapping data for Christin and Dominik. In all cases, $100 \%$ of the data exceeded the median (PEM, Ma, 2006) and the median trend (PEM-T, Wolery, Busick, Reichow, \& Barton, 2010). A piecewise regression analyses (Huitema \& McKean, 2000) for the four students yielded the results shown in Table 1.

Table 1. Piecewise regression model for TWW (Level 1 Analysis)

\begin{tabular}{|c|c|c|c|c|c|}
\hline & $B$ & $S E$ & $t$ & $p$ & $R^{2}$ \\
\hline \multicolumn{6}{|c|}{ Adrian } \\
\hline Intercept & 110.50 & 108.75 & 1.02 & 0.339 & \\
\hline Trend & -17.00 & 29.60 & -0.57 & 0.582 & 0.01 \\
\hline Level Phase B & -87.00 & 88.80 & -0.98 & 0.356 & 0.02 \\
\hline Level Phase A2 & -406.00 & 86.29 & -4.70 & 0.002 & 0.39 \\
\hline Slope Phase B & 114.30 & 36.25 & 3.15 & 0.014 & 0.17 \\
\hline Slope Phase A2 & -93.90 & 29.60 & -3.17 & 0.013 & 0.18 \\
\hline \multicolumn{6}{|c|}{ Bella } \\
\hline Intercept & 124.50 & 59.45 & 2.09 & 0.066 & \\
\hline Trend & -15.50 & 17.93 & -0.87 & 0.410 & 0.00 \\
\hline Level Phase B & 45.90 & 73.91 & 0.62 & 0.550 & 0.00 \\
\hline Level Phase A2 & -559.20 & 73.91 & -7.57 & 0.000 & 0.32 \\
\hline Slope Phase B & 129.80 & 25.35 & 5.12 & 0.001 & 0.15 \\
\hline Slope Phase A2 & -116.70 & 25.35 & -4.60 & 0.001 & 0.12 \\
\hline \multicolumn{6}{|c|}{ Christin } \\
\hline Intercept & 123.70 & 72.82 & 1.70 & 0.124 & \\
\hline Trend & -14.90 & 21.96 & -0.68 & 0.514 & 0.01 \\
\hline Level Phase B & 138.70 & 90.52 & 1.53 & 0.160 & 0.05 \\
\hline Level Phase A2 & -311.00 & 90.52 & -3.44 & 0.007 & 0.27 \\
\hline Slope Phase B & 44.80 & 31.05 & 1.44 & 0.183 & 0.05 \\
\hline Slope Phase A2 & -24.30 & 31.05 & -0.78 & 0.454 & 0.01 \\
\hline \multicolumn{6}{|c|}{ Domenik } \\
\hline Intercept & 43.00 & 37.50 & 1.15 & 0.281 & \\
\hline Trend & -4.00 & 11.31 & -0.35 & 0.732 & 0.00 \\
\hline Level Phase B & -53.20 & 46.62 & -1.14 & 0.283 & 0.00 \\
\hline Level Phase A2 & -441.00 & 46.62 & -9.46 & 0.000 & 0.30 \\
\hline Slope Phase B & 117.40 & 15.99 & 7.34 & 0.000 & 0.18 \\
\hline Slope Phase A2 & -124.80 & 15.99 & -7.81 & 0.000 & 0.21 \\
\hline
\end{tabular}

As indicated in Table 1, there were no developmental trends in phase A1. In addition, there were no noteworthy level effects from phase A1 to phase B. However, the steepness of the regression lines differed significantly in all cases except for that of Christin (from A1 to B and from B to A2). The first baseline phase could be considered stable, and there was a continuous treatment effect for Adrian, Bella, and Domenik in the B phase. These three participants continued to improve their performance as the motivational intervention proceeded. As soon as the college student stopped applying explicit timing, requiring self-scoring, and displaying the high scores, the participants' achievements ceased. In fact, all participants (including Christin) demonstrated a sudden decline in their output upon the termination of the treatment, as represented in significant level effects between phases B and A2.

To complete the statistical data analysis, the four cases were aggregated into one using hierarchical linear modeling (see Table 2). Overall, the motivational system seemed to elicit a significant continuous treatment effect, which immediately vanished as soon as the intervention was over. 
Table 2. Piecewise regression model for TWW (Level 2 Analysis)

\begin{tabular}{lccccc}
\hline & $B$ & $S E$ & $d f$ & $t$ & $p$ \\
\hline Intercept & 91.44 & 42.26 & 50 & 2.16 & 0.035 \\
Trend & -10.60 & 11.33 & 50 & -0.94 & 0.354 \\
Level Phase B & 8.85 & 44.22 & 50 & 0.20 & 0.842 \\
Level Phase A2 & -429.30 & 44.01 & 50 & -9.76 & 0.000 \\
Slope Phase B & 99.33 & 15.57 & 50 & 6.38 & 0.000 \\
Slope Phase A2 & -89.93 & 15.11 & 50 & -5.95 & 0.000 \\
\hline
\end{tabular}

All students reported that they enjoyed the challenge of trying to beat their previous high scores. They indicated that they usually did not like to write but that the use of the timer and the visibility of their improvements made it much easier for them to attend to the task. They regretted that the college student stopped the motivational system after only one week and stated that they hoped to participate in a project such as this again.

\section{Discussion}

The results of this study suggest that a motivational system (consisting of explicit timing, self-scoring, and displaying high scores) has the potential to help students with learning disabilities to write considerably longer stories than they would otherwise. All four participants in this research wrote longer texts in the last trial of the B phase than in any previous trial during the experiment. Every effect-size index (PND, PEM, PEM-T) indicates a very beneficial treatment outcome, with scores between 80 and $100 \%$. Even though the slope effect did not reach statistical significance for Christin, a visual inspection of her performance curve in the B phase still suggests that she benefited from the intervention. In addition, the subjects gave very favorable feedback on the treatment during the informal interviews at the end of the study.

Despite these positive effects, a number limitations of this research should be acknowledged to put the findings in context. First, as only four participants were included, involving more individuals would have strengthened the results and made them more generalizable to the population that Adrian, Bella, Christin, and Dominik were drawn from. Second, the phases were all rather brief. Thus, it is possible that the motivational system would have lost its potency if it had been implemented for longer. The results provide no way of telling how the increase in word production would have developed had the intervention continued for another week or two. It is certainly conceivable that the students would have lost interest in writing stories. A third limitation pertains to the fact that the motivational system was evaluated as a whole, which means that there is no way to determine the isolated benefits of any of the three treatment elements. Fourth, the ABA design does not end on a high note, as the potentially effective intervention is withdrawn in the last step. Subsequently, the participants are left to their own resources and do not receive any further help (Ledford \& Gast, 2018). The final critical issue relates to the way in which the dependent variable was measured. Although TWW is certainly a very common index, it is not the only option for capturing writing performance. Future studies should utilize not only TWW, but also other measures like the number of correct word sequences (CWS) or different writing rubrics (see, e.g., Gansle, Noell, VanDerHeyden, Naquin, \& Slider, 2002) - to determine the effectiveness of writing interventions like the one described in this paper. In particular, tools that focus on more than just productivity could be of unique interest. Beyond that, it could be helpful to incorporate such scoring methods into the intervention by employing them to give students continuous feedback on the level of appropriate word choice, the organization of the produced texts, and other indicators. Providing struggling writers frequently with information on how well they are doing might elicit a further increase in performance and help them sustain the developed skills (see e.g. McKeown, Kimball, \& Ledford, 2015).

Despite its limitations, this study represents additional empirical support for the use of explicit timing, self-scoring, and displaying high scores for overcoming resistance to writing among students with learning disabilities. Finding ways to encourage these children and adolescents to complete a task that they usually detest is certainly a great challenge. This experiment, however, provides reason for optimism, as its results indicate that it does not require much effort to provide these students with motives to engage in text production. To create proficient writers, it is certainly not enough to encourage learners to compose simple stories. That is only the start. Custom interventions based on the aforementioned SRSD model (or on other sound approaches) need to apply scaffolding to help struggling students on their paths to becoming skillful at producing not only plain narratives but also more elaborate texts.

In conclusion, the advantage of this study is its potential to help learners accomplish a crucial subgoal (engaging in 
text composition) with rather little effort. The expense of the intervention was minimal. Most classrooms have timers. Plastic folders and notebook paper are inexpensive. Each session took only few minutes and thus was very efficient. It remains to be seen whether the motivational system evaluated in this study will receive a wide distribution in everyday writing education for students with learning disabilities (or other challenged students). Researchers thus need to address the questions that this experiment has left unanswered.

\section{References}

Archer, A. L., \& Hughes, C. A. (2011). Explicit instruction: Effective and efficient teaching. New York, NY: Guildford.

Bereiter, C., \& Scardamalia, M. (1987). The psychology of written composition. Hillsdale, NJ: Erlbaum.

Cook, K. B., \& Bennett, K. E. (2014). Writing interventions for high school students with disabilities: A review of single-case design studies. Remedial and Special Education, 35, 344-355. https://doi.org/10.1177/0741932514523140

Datchuk, S. M., \& Kubina, R. M. (2013). A review of teaching sentence-level writing skills to students with writing difficulties and learning disabilities. Remedial and Special Education, 34, 180-192. https://doi.org/10.1177/0741932512448254

De Caso, A.-M., \& García, J.-N. (2006). What is missing from current writing intervention programs? The need for writing motivation programs. Estudios de Psicología, 27, 221-242. https://doi.org/10.1174/021093906777571682

De La Paz, S. (2001). STOP and DARE: A persuasive writing strategy. Intervention in School and Clinic, 36, 234-243. https://doi.org/10.1177/105345120103600409

Duhon, G. J., House, S., Hastings, K., Poncy, B., \& Solomon, B. (2015). Adding immediate feedback to explicit timing: An option for enhancing treatment intensity to improve mathematics fluency. Journal of Behavioral Education, 24, 74-87. https://doi.org/10.1007/s10864-014-9203-y

Fayol, M., Alamargot, D., \& Berninger, V. W. (2012). Translation of thought to written text while composing. New York, NY: Taylor \& Francis. https://doi.org/10.4324/9780203141434

Furey, W. M., Marcotte, A. M., Hintze, J. M., \& Shackett, C. M. (2016). Concurrent validity and classification accuracy of curriculum-based measurement for written expression. School Psychology Quarterly, 31, 369-382. https://doi.org/10.1037/spq0000138

Gansle, K. A., Noell, G. H., VanDerHeyden, A. M., Naquin, G. M., \& Slider, N. J. (2002). Moving beyond total words written: The reliability, criterion validity, and time cost of alternate measures for curriculum-based measurement in writing. School Psychology Review, 31, 477-497.

Gillespie, A., \& Graham, S. (2014). A meta-analysis of writing interventions for students with learning disabilities. Exceptional Children, 80, 454-473. https://doi.org/10.1177/0014402914527238

Graham, S., \& Harris, K. R. (1996). Teaching writing strategies within the context of a whole language class. In E. McIntyre, \& M. Pressley (Eds.), Balanced instruction: Strategies and skills in whole language (pp. 155-175). New York, NY: Christopher-Gordon.

Graham, S., MacArthur, C. A., \& Fitzgerald, J. (2013). Best practices in writing instruction. New York, NY: Guilford.

Grays, S. D., Rhymer, K. N., \& Swartzmiller, M. D. (2017). Moderating effects of mathematics anxiety on the effectiveness of explicit timing. Journal of Behavioral Education, 26, 188-200. https://doi.org/10.1007/s10864-016-9251-6

Grünke, M., \& Morrison Cavendish, W. (2016). Learning disabilities around the globe: Making sense of the heterogeneity of the different viewpoints. Learning Disabilities: A Contemporary Journal, 14, 1-8.

Grünke, M., Knaak, T., \& Hisgen, S. (2018). The effects of a class-wide multicomponent motivational intervention on the writing performance of academically challenged elementary school students. Insights on Learning Disabilities, 15, 85-100.

Grünke, M., Sperling, M., \& Burke, M. D. (2017). The effects of immediate feedback, explicit timing, and positive reinforcement on the writing performance of struggling 5th grade students in Germany. Insights into Learning Disabilities, 14, 135-153.

Hayes, J., \& Flower, L. (1980). Identifying the organization of writing processes. In L. Gregg \& E. Steinberg 
(Eds.), Cognitive processes in writing (pp. 3-30). Hillsdale, NJ: Erlbaum.

Huitema, B. E., \& McKean, J. W. (2000). A simple and powerful test for autocorrelated errors in OLS intervention models. Psychological Reports, 87, 3-20. https://doi.org/10.2466/pr0.2000.87.1.3

Kaldenberg, E. R., Ganzeveld, P., Hosp, J. L., \& Rodgers, D. B. (2016). Common characteristics of writing interventions for students with learning disabilities: A synthesis of the literature. Psychology in the Schools, 53, 938-953. https://doi.org/10.1002/pits.21958

Ledford, J. R., \& Gast, D. L. (2018). Single case research methodology: Applications in special education and behavioral sciences. London, England: Routledge. https://doi.org/10.4324/9781315150666

Light, L. C., McKeachie, W. J., \& Lin, Y.-G. (1988). Self-scoring: A self-monitoring procedure. Teaching of Psychology, 15, 145-147. https://doi.org/10.1207/s15328023top1503_11

Ma, H. H. (2006). An alternative method for quantitative synthesis of single-subject researches: Percentage of data points exceeding the median. Behavior Modification, 30, 598-617. https://doi.org/10.1177/0145445504272974

Marks, A. (2012). 100 story starters: Writing prompts to jump-start your imagination [Kindle DX version]. Retrieved from http://www.amazon.com

Mason, L. H., Harris, K. R., \& Graham, S. (2004). POW + WWW, What $=2$, How $=2$ equals fun and exciting stories. Teaching Exceptional Children, 36, 70-73.

McDaniel, S. C., Jolivette, K., \& Ennis, R. P. (2013). The effects of self-graphing on oral reading fluency for a student with E/BD within an alternative education school. Journal of the American Academy of Special Education Professionals, 8, 69-82.

McKeown, D., Kimball, K., \& Ledford, J. (2015). Effects of asynchronous audio feedback on the story devision practices of students with emotional/behavioral disorders. Education and Treatment of Children, 38, 541-564.

McMaster, K., \& Espin, C. (2007). Technical features of curriculum-based measurement in writing: A literature review. Journal of Special Education, 41, 68-84. https://doi.org/10.1177/00224669070410020301

National Commission on Writing for America's Families, Schools, and Colleges. (2004, September). Writing: A ticket to work ... or a ticket out: A survey of business leaders. Retrieved from http://www.collegeboard.com

Prater, M. A. (2018). Teaching students with high incidence disabilities. Thousand Oaks, CA: Sage.

Rogers, L., \& Graham, S. (2008). A meta-analysis of single subject design writing intervention research. Journal of Educational Psychology, 100, 879-906. https://doi.org/10.1037/0022-0663.100.4.879

Santangelo, T. (2014). Why is writing so difficult for students with learning disabilities? A narrative review to inform the design of effective instruction. Learning Disabilities: A Contemporary Journal, 12, 5-20.

Scruggs, T. E., \& Mastropieri, M. A. (1998). Summarizing single-subject research. Issues and applications. Behavior Modification, 22, 221-242. https://doi.org/10.1177/01454455980223001

Sherman, C. K., \& De La Paz, S. (2015). FIX: A strategic approach to writing and revision for students with $\begin{array}{llll}\text { learning disabilities. } & \text { Teaching }\end{array}$ https://doi.org/10.1177/0040059918757944

Tawney, J. W., \& Gast, D. L. (1984). Single subject research in special education. Columbus, OH: Merrill.

Troia, G. A. (2010). Instruction and assessment for struggling writers. New York, NY: Guilford.

Troia, G. A., Shankland, R. K., \& Wolbers, K. A. (2012). Motivation research in writing: Theoretical and empirical considerations. Reading \& Writing Quarterly, 28, 5-28. https://doi.org/10.1080/10573569.2012.632729

Van Houten, R., \& McKillop, C. (1977). An extension of the effects of the performance feedback system with secondary school students. Psychology in the Schools, 14, 480-484. https://doi.org/10.1002/1520-6807(197710)14:4<480::AID-PITS2310140420>3.0.CO;2-B

Van Houten, R., \& Thompson, C. (1976). The effects of explicit timing on math performance. Journal of Applied Behavior Analysis, 9, 227-230. https://doi.org/10.1901/jaba.1976.9-227

Van Houten, R., Hill, H., \& Parsons, M. (1975). An analysis of a performance feedback system: The effects of timing and feedback, public posting, and praise upon academic performance and peer interaction. Journal of 
Applied Behavior Analysis, 8, 449-457. https://doi.org/10.1901/jaba.1975.8-449

Van Houten, R., Morrison, E., Jarvis, R., \& MacDonald, M. (1974). The effects of explicit timing and feedback on compositional response rate in elementary school children. Journal of Applied Behavior Analysis, 7, 547-555. https://doi.org/10.1901/jaba.1974.7-547

Wells, J. C., Sheehey, P. H., \& Sheehey, M. (2017). Using self-monitoring of performance with self-graphing to increase academic productivity in math. Beyond Behavior, 26, 57-65. https://doi.org/10.1177/1074295617711207

Wilbert, J. (2018). Package 'Scan': Single-case data analyses for single and multiple AB designs. Retrieved from https://www.uni-potsdam.de/fileadmin01/projects/inklusion/scan/scan.pdf

Wolery, M., Busick, M., Reichow, B., \& Barton, E. (2010). Comparison of overlap methods for quantitatively synthesizing single-subject data. Journal of Special Education, 44, 18-28. https://doi.org/10.1177/0022466908328009

Zimmerman, B. J., \& Risemberg, R. (1997). Becoming a self-regulated writing: A social cognitive perspective. Contemporary Educational Psychology, 22, 73-101. https://doi.org/10.1006/ceps.1997.0919

\section{Copyrights}

Copyright for this article is retained by the author(s), with first publication rights granted to the journal.

This is an open-access article distributed under the terms and conditions of the Creative Commons Attribution license (http://creativecommons.org/licenses/by/4.0/). 